\title{
Eventos de bicicleta de montanha em Portugal: características, distribuição temporal e espacial e ocorrência sobre a rede nacional de áreas protegidas e classificadas \\ Mountain biking events in Portugal: characteristics, temporal and spatial distribution and occurrence over the national network of classified and protected areas \\ Eventos de bicicleta de montaña en Portugal: características, distribución temporal y espacial e incidencia en la red nacional de áreas protegidas y clasificadas \\ *\&** Ricardo Manuel Nogueira Mendes, *Estela Inés Farías Torbidoni, **Carlos Pereira da Silva \\ *Universitat de Lleida (España), **Universidade Nova de Lisboa (Portugal)
}

Resumo. O aumento de práticas desportivas em áreas protegidas e classificadas é inegável. O carácter difuso e informal de algumas modalidades como a bicicleta de montanha ou o trail running realizadas nestes territórios difículta o seu estudo e monitorização. Nesse sentido, estudar eventos desportivos destas modalidades pode ajudar à obtenção de informação essencial para uma boa gestão dos usos recreativos nestes territórios. Através da sistematização e posterior georreferenciação de 677 eventos de bicicleta de montanha ocorridos em 2018 em Portugal, foi possível identificar algumas das suas principais características. As Maratonas/Raids/Rotas competitivas e os Passeios não competitivos são as submodalidades ou tipologias que reúnem maior oferta e mais participantes. A sua distribuição é nacional e caracterizam-se por terem em média, apesar de existir uma certa variabilidade por tipologia, 1,5 percursos, 50,6 km e 228 participantes. Em termos sazonais, a maioria dos eventos realiza-se nos períodos de Primavera e Outono. Uma vez que 29,7\% do território nacional está incluído no sistema nacional de áreas classificadas e que $62,9 \%$ dos eventos ocorrem dentro ou na proximidade destas, é evidente que estes territórios desempenham um papel importante na distribuição da oferta, reforçando a importância deste estudo.

Palavras-chave: BTT; eventos desportivos; distribuição espacial; actividades de ar livre; áreas protegidas.

\begin{abstract}
The increase of sports activities such as mountain biking or trail running in protected and classified areas is undeniable. Due to its diffuse and informal nature, monitoring the effects that they cause in these territories is difficult, therefore the study of its sports events can be a good opportunity to build a national image on these modalities in the view of future management. Through the systematization and subsequent georeferencing of 677 mountain bike events that took place in 2018 in Portugal, it was possible to identify some of its main characteristics. Competitive Marathons/Raids/Routes and non-competitive Tours are the submodalities or typologies that bring together the greatest offer and most participants. Its distribution is national and is characterized by having on average, although with a certain variability by typology, 1.5 courses, $50.6 \mathrm{~km}$, and 228 participants. In seasonal terms, most events take place in the spring and autumn periods. Since $29.7 \%$ of the national territory is included in the national system of classified areas and $62.9 \%$ of the events take place in or near these, it is evident that these territories play an important role in the distribution of the offer, reinforcing the importance of this study.
\end{abstract}

Keywords: MTB; sport events; spatial distribution; outdoor activities; protected area.

Resumen. El incremento de las prácticas deportivas en áreas protegidas y clasificadas es innegable. El carácter difuso e informal de algunas modalidades como la bicicleta de montaña o trail running practicadas en estos territorios dificulta su estudio y seguimiento. En este sentido, el estudio de eventos deportivos de estas modalidades puede ayudar a obtener información esencial para una buena gestión de los usos recreativos de estos territorios. A través de la sistematización y posterior georreferenciación de 677 eventos de bicicleta de ocurridos el año 2018 en Portugal, fue posible identificar algunas de sus características principales. Las Maratones/Raids/Rutas competitivas y las Marchas no competitivas son las submodalidades o tipologías que reúnen el mayor número de oferta y participantes. Se distribuyen a lo largo de todo el territorio y se caracterizan por incluir una media de, a pesar de una cierta variabilidad según tipologías, 1,5 recorridos, $50,6 \mathrm{~km}$ y 228 participantes. En términos estacionales, la mayoría de los eventos tienen lugar en los períodos de primavera y otoño. Teniendo en cuenta que el $29,7 \%$ del territorio nacional está incluido en el sistema nacional de áreas clasificadas y el $62.9 \%$ de los eventos tienen lugar dentro o cerca de estas es evidente que estos territorios desempeñan un papel importante en la distribución de la oferta, reforzando la importancia de este estudio.

Palabras clave: bicicleta de montaña; eventos deportivos; distribución espacial; actividades de outdoor; áreas protegidas.

\section{Introdução}

Fruto da maior disponibilidade de tempo livre, têm-se observado nas sociedades ocidentais uma verdadeira massificação da prática de actividades desportivas ao ar livre. Fazer qualquer tipo de actividade física é saudável, está na moda e muitos são os que procuram aliar os deportos de ar livre com espaços naturais por se sentirem conectados com o meio natural (Brown, 2016; Fuster Matute, Farías Torbidoni, Gil, \& Seguí Urbaneja, 2014; Julião, Farías Torbidoni, Valente,

Fecha recepción: 12-03-20. Fecha de aceptación: 08-06-20 Ricardo Manuel Nogueira Mendes

rnmendes@fcsh.unl.pt
\& Mendes, 2018). De entre as várias razões indicadas para a prática desportiva de acordo com o Eurobarómetro (European Union, 2018) estão a melhoria das condições de saúde (54\%) e de condição física (47\%), secundadas pelo relaxamento (38\%) e a diversão (30\%), o que de alguma maneira ajuda a explicar este fenómeno actual.

A nível internacional esses factos têm sido evidenciados por estudos como o «National Survey on Recreation and the Environment» dos Estados Unidos da América (NSRE, 20002002) onde num universo $213,1 \mathrm{M}$ de indivíduos, $183,3 \mathrm{M}$ são praticantes regulares de passeios a pé ao ar livre e 87,2 $\mathrm{M}$ praticantes de ciclismo, dos quais $48.4 \mathrm{M}$ indicam que o fazem em trilhos ou estradas rurais. A nível europeu apesar 
de não existir nenhum estudo com a mesma profundidade, sabe-se que $40 \%$ da população faz exercício físico de forma regular pelo menos uma vez por semana e destes, $40 \%$ preferem espaços de ar livre por oposição às instalações desportivas, valor que atinge os $67 \%$ na Finlândia (European Union, 2018). O mesmo estudo indica ainda que apenas $3 \mathrm{em}$ cada 10 dos inquiridos se enquadram numa estrutura do género clube desportivo, ginásio ou outro, sugerindo que $70 \%$ das práticas desportivas na Europa são feitas de forma informal e na maioria dos casos ao ar livre.

De entre estas, a bicicleta de montanha ou bicicleta de todo-o-terreno (BTT), desenvolvida nos Estados Unidos da América na década de 1970 e que chegou à Europa no início dos anos 80 (Savre, Saint-Martin, \& Terret, 2010) é provavelmente a rainha das actividades recreativas de elevada intensidade física (Ainsworth et al., 2011). Considerada um nicho de mercado no início da década de noventa, o número de praticantes de BTT no Nordeste Americano duplicou (Warnick, 2005), e ainda que a versão mais recente do NSRE sugira uma queda de praticantes na região norte dos EUA, esta actividade continua a ser praticada por $20 \%$ da população (Cordell, Betz, Mou, \& Gormanson, 2012). Na Europa não existe nenhum censo do mesmo género, mas existem alguns dados que reforçam a importância do BTT. Num estudo realizado pela International Mountain Biking Association (IMBA) Europe realizado entre Abril e Maio de 2015 , com 6057 participantes (dos quais 52\% responderam à totalidade do inquérito) são deixadas algumas pistas relevantes. A principal razão para a prática do BTT é a fruição da natureza, numa atitude de escape à rotina do dia-a-dia, sendo comum a prática de outras actividades como o pedestrianismo, as actividades de neve ou a corrida. Para a totalidade da amostra, em média, cada praticante tem 1,9 bicicletas, no valor de 2546 • comprada a cada 4,04/Anos. Cada praticante dedica 6,9 saídas por mês, que duram em média 2 h36 perfazendo 82,8 saídas e mais e $215 \mathrm{~h}$ de prática anuais. Com uma média de prática de 8,4 anos de experiência, a idade média dos respondentes foi de 24 Anos (mais baixa que o esperado) o que pode ser justificado pelo facto da dinamização do inquérito ter sido feita sobretudo através de clubes de praticantes. Existe uma razoável pré-disposição para o pagamento de taxas de utilização desde que as receitas sejam usadas no desenvolvimento e manutenção de trilhos e $87 \%$ dos respondentes considera importante o trabalho voluntário dedicado à manutenção dos mesmos (IMBA Europe, 2015). Existe uma clara preferência por trilhos singletracks e onde se possam contornar os obstáculos (naturais ou artificiais) normalmente referidos como technical trail features (Kollar, 2011).

Tal como verificaram Pickering, Hill, Newsome, \& Leung (2010) para a Austrália e os Estados Unidos também em Portugal o BTT é uma actividade popular em áreas remotas e urbanas sobretudo próximas de áreas protegidas não só pelo facto de poder ser praticada com regularidade ao longo de todo o ano, mas por ser também acessível em termos de exigência física, custos e equipamento por comparação com outras modalidades. Dados gerais sobre o tema, são poucos, sobretudo fora do âmbito competitivo que é enquadrado pela Federação Portuguesa de Ciclismo (UVP-FPC) que contava em 2018 com 16448 filiados, 15 associações regionais e 749 clubes e/ou grupos-equipa (Federação Portuguesa de Ciclismo, 2018). Apesar de poucos filiados há, no entanto, provas inequívocas da sua importância. Desde 1999 que o BTT é reconhecido pelo Instituto de Conservação da Natureza e das Florestas e pelo Turismo de Portugal como actividade de Desporto de Natureza, sendo recorrentemente indicado como produto de vocação estratégica para o País. Nesse sentido, o BTT é uma prática desejável nas áreas protegidas e classificadas, havendo várias iniciativas de criação e promoção de rotas e trilhos turísticos, eventos, etc. No âmbito das actividades recreativas em geral, está incluído nos seus planos de ordenamento e de gestão, sendo muitas vezes apontado como instrumento de desenvolvimento local e regional. Fruto de uma utilização massiva nas últimas três décadas, existem também registos e relatos de impactos e conflitos ligados tanto às actividades recreativas em geral como ao BTT em particular.

Em Portugal 29,71\% dos $92226 \mathrm{~km}^{2}$ da área terrestre do País estão incluídos no âmbito do Sistema Nacional de Áreas Classificadas (SNAC), valor que varia entre os $29,58 \%$ para o território de Portugal Continental, os 24,17\% para os Açores e os 59,44\% da Madeira representando um vasto território para a modalidade (Figura 1). Em relação ao SNAC, este engloba a Rede Nacional de Áreas Protegidas (RNAP), a Rede Natura 2000 (que incluí as Zonas de Protecção Especial e os Sítios de Importância Comunitária e da Lista Nacional), os Sítios Classificados ao abrigo da Convenção de Ramsar, e as Reservas da Biosfera que ocupam 8,26\%, 21,11\% $1,28 \%$ e $12,20 \%$ do território de Portugal Continental respectivamente. Uma vez que algumas destas classificações são justapostas em termos de território, o valor total do SNAC perfaz os $29,71 \%$ já indicados.

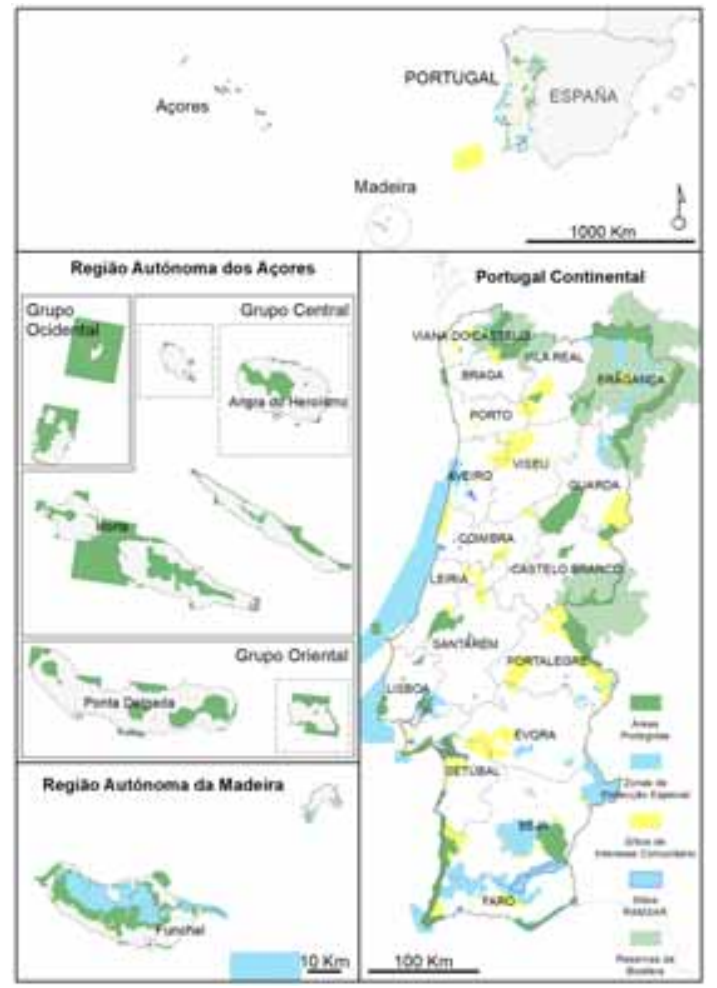

Figura 1. Área de estudo e Sistema Nacional de Áreas Classificadas de Portugal

Para além da prática informal e individual do BTT que se espalha por todo o Pais realizam-se por ano, quer no Conti- 
nente quer nas regiões autónomas, centenas de eventos promovidos por diferentes actores como clubes, associações locais, etc., com o apoio ou o envolvimento directo de entidades públicas e do poder local. Eventos deste género, ao atrair participantes pretendem também promover a imagem local (Parra Camacho, Calabuig Moreno, Añó Sanz, Ayora Pérez, \& Núñez Pomar, 2014) sendo por isso apoiados no âmbito de políticas de desenvolvimento desportivo e/ou turístico. Com o objectivo de se enraizarem e criarem uma marca própria, muitos destes eventos utilizam nomes de aspectos culturais, locais emblemáticos ou produtos locais, numa perspectiva de marketing territorial por vezes associados aos campeonatos diferentes tipologias do BTT. Face ao reduzido número de praticantes filiados é normal, mesmo nos eventos federados do calendário nacional e internacional, que estes funcionem em formato «open» (i.e. abertos, a praticantes não federados) existindo ainda muitos outros sem um verdadeiro carácter competitivo simplesmente chamados «passeios». Num misto entre a prática desportiva e o espírito de aventura, existem também alguns eventos que funcionam como um serviço de animação turística, dos quais se destaca a TransPortugal (iniciada em 2003 e com custos a rondar os 2000•) e que chegam a atrair mais participantes estrangeiros do que nacionais.

Pelo facto da maioria da prática do BTT ser de carácter informal, muitas vezes organizado em torno de redes sociais como páginas de Facebook, grupos do STRAVA, ou simples grupos de amigos é difícil construir uma imagem actual da actividade em todas as suas dimensões. Segundo LopézCarril, Villamanón \& Añó (2019) as redes sociais merecem cada vez mais atenção em torno da gestão do desporto pelo partido que retiram das suas múltiplas características (identidade, reputação, partilha, etc.).

Para além do facto de as áreas protegidas ou áreas rurais serem territórios com grande potencialidade para a prática da modalidade, não se sabe em Portugal quantos praticantes regulares existem, qual o número total de eventos, qual o valor económico do sector ou qual é a verdadeira dimensão dos impactos económicos e ambientais que gera directamente. Pontualmente alguns trabalhos abordaram alguns destes temas. A intensidade de utilização foi já determinada para alguns territórios da área metropolitana de Lisboa por (Campelo \& Nogueira Mendes, 2016; Nogueira Mendes, Silva, Grilo, Rosalino, \& Pereira da Silva, 2012; Santos, Nogueira Mendes, \& Vasco, 2016), e Nogueira Mendes \& Pereira da Silva, (2016) tentaram caracterizar os praticantes de BTT através de um evento de um Parque Natural.

Por norma, os eventos desportivos são um indicador da prática e da popularidade de modalidades desportivas (Farías, Seguí, Mena, \& Sabaté, 2017), mesmo que a atitude da maioria dos praticantes seja a simples prática recreativa. Nesse sentido, caracterizar e monitorizar o número de eventos, quantificar o número de participantes e respectivos perfis, perceber a sua distribuição espacial, etc., pode ajudar a compreender e gerir a esta modalidade e servir de modelo para estudos semelhantes.

Pelo acima exposto o objectivo genérico deste trabalho é a construção da imagem nacional dos eventos de BTT em Portugal, na tentativa de estabelecer um ponto de partida para a gestão e monitorização desta modalidade, sobretudo nos territórios de maior sensibilidade ambiental. Nesse sentido são objectivos em particular 1) Inventariar e caracterizar os eventos de BTT em Portugal; 2) Analisar a sua distribuição temporal; 3) Avaliar a distribuição espacial e ocorrência dos eventos de BTT em relação à sistema nacional de áreas classificadas.

\section{Material e métodos}

$\mathrm{Na}$ falta de um conjunto de dados devidamente organizados sobre os eventos de BTT em Portugal construiu-se uma base dados de todos os eventos realizados em 2018 com recurso a dados secundários a partir de empresas de cronometragem, páginas de Facebook, blogs de divulgação, bem como os calendários da UVP-FPC e demais associações regionais. As buscas foram feitas usando como referência os termos «BTT» « «2018» tendo sido identificadas um total e 20 fontes que são apresentadas na Tabela 1 .

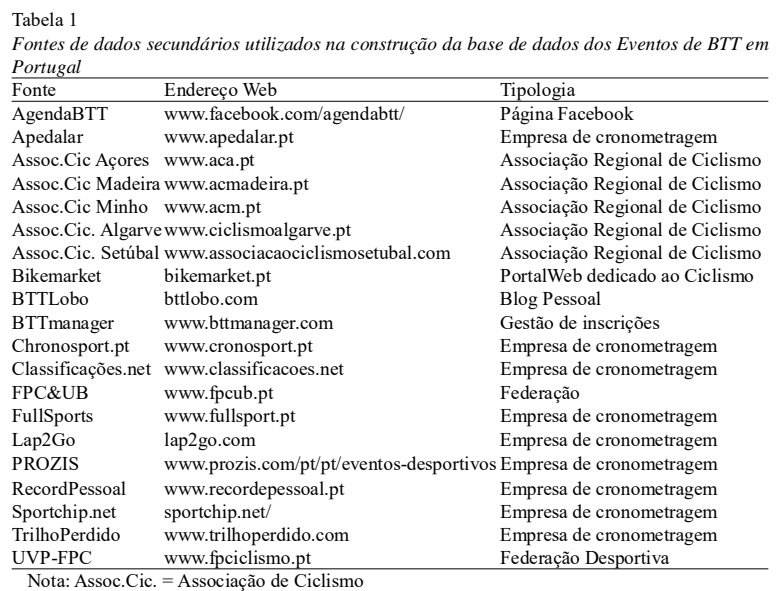

Para cada evento identificado foram recolhidos de forma sistemática os seguintes elementos: Nome; Tipologia; Número de percursos; Distâncias dos percursos; Número de inscritos; Preço de inscrição; Carácter competitivo (i.e. incluídos num calendário desportivo ou não); Data; Número da edição; Local. Na maioria dos casos, a partir do nome do evento foram directamente identificados a edição e a tipologia. Por exemplo a «12 $2^{\mathrm{a}}$ Maratona BTTascaduXico», correspondia à $12^{\mathrm{a}}$ edição de uma maratona de BTT. As tipologias foram classificadas de acordo com: XCM (que incluí Maratonas, Raids e Rotas); Passeio, em tudo semelhantes à tipologia anterior, mas sem caracter competitivo, i.e. sem pódios; XCR (Resistência); XCO (Cross Country Olímpico); Challenge (eventos de distâncias longas normalmente feitas em etapas); Enduro (All-Mountain); Downhill; Uphill; Contra-Relógio. Foram ainda anotados os eventos de XCM e Passeios que de forma evidente incluíam a participação de bicicletas eléctricas nalgum dos percursos postos à disposição dos participantes.

Sempre que a informação do evento foi insuficiente para o preenchimento completo da base de dados original, recorreu-se à procura dos dados em falta junto de outras fontes na web, nomeadamente outras páginas de Facebook, páginas de internet dos próprios promotores das provas, juntas de freguesia, câmaras municipais e órgãos de informação de âmbito local ou regional que mencionavam 
directamente o evento.

O número de edição foi convertido no primeiro ano de realização do evento com o objectivo de analisar a idade média, bem como a evolução do número de novas provas ao longo das últimas décadas. Na falta de uma base de dados devidamente sistematizada como as utilizadas por Farías Torbidoni (2015) e Segui Urbaneja \& Farías Torbidoni (2018), esta abordagem deve ser encarada como uma aproximação uma vez que não detecta eventuais interrupções nem eventos que tenham deixado de existir.

Ao local do evento foi atribuído um par de coordenadas LatLong (WGS84) no sentido de construir um sistema de informação geográfica para a posterior análise de modelação dos eventos tendo em conta a sua distribuição regional e proximidade aos territórios classificados do SNAC. Para os eventos em que as coordenadas do local de partida não eram directamente facultadas pela própria página de informação/ divulgação do evento, a georreferenciação foi feita com recurso à ferramenta de importação do software Google Earth PRO, tendo por base o nome da localidade, o concelho e respectivo distrito. Todos os pontos georreferenciados foram validados recorrendo à cartografia do Google Maps e da Direcção Geral do Território para mitigar eventuais erros originados pelo processo de georreferenciação.

Para a avaliar o papel das áreas protegidas na distribuição dos eventos de BTT foram identificados aqueles cujo local de início da prova se realizou dentro, ou numa distância de até $5 \mathrm{~km}$ de uma área protegida ou classificada. Uma vez que a maioria dos eventos identificados pertencem às tipologias de XCM ou Passeios, considerou-se que dentro desta distância é natural que o percurso se dirija e atravesse estes territórios que face ao seu entorno contem uma oferta de «fora de estrada» mais agradável para o BTT (estradões, trilhos, mais altimetria, etc.).

O objectivo desta análise foi apenas identificar, ainda que de forma empírica, a atractividade destes territórios para o desenvolvimento de eventos desportivos, deixando para futuros trabalhos a avaliação de eventuais impactos ambientais. Face à legislação em vigor, a realização destes eventos obriga ao licenciamento junto de diferentes entidades (incluindo a entidade gestora das próprias áreas protegidas, municípios, forças de socorro e segurança), pelo que quaisquer impactos ambientais graves estão à partida acautelados. Além disso, uma verdadeira análise de impactos (ambientais e/ou outros) teria de ser feita a partir dos trajectos e tendo em conta a rede viária, os planos e ordenamento e/ou objectivos de gestão das áreas protegidas e classificadas, bem como os perfis e número de participantes e utilizadores habituais da região, etc.

\section{Resultados}

No total foram inventariados 677 eventos de BTT para os quais se identificaram correctamente as características indicadas na Tabela 2.

\section{Características principais}

Tipologias de eventos, número de percursos, inscritos $e$ preços

O resumo dos dados apurados para o número de
Tabela 2

Características genéricas dos dados recolhidos.

\begin{tabular}{lcc} 
& & \\
\hline Característica & N. ${ }^{\circ}$ de eventos cuja característica foi determinada & $\%$ \\
\hline Nome & 677 & $100 \%$ \\
Tipologia & 677 & $100 \%$ \\
Número de percursos & 474 & $70 \%$ \\
Distáncias dos percursos & 474 & $70 \%$ \\
Número de inscritos & 326 & $48 \%$ \\
Preço & 278 & $41 \%$ \\
Incluído num calendário desportivo & 214 & $32 \%$ \\
Data & 677 & $100 \%$ \\
Edição & 374 & $55 \%$ \\
Local & 677 & $100 \%$ \\
\hline
\end{tabular}

Local

$100 \%$

percursos, de inscritos e de preços por tipologia dos eventos são apresentados na Tabela 3. Dos 677 eventos identificados e de entre as 9 tipologias consideradas, a que maior frequência de eventos congregou em 2018 em Portugal foi a $\mathrm{XCM}$ com 38,4\% seguida dos Passeios que atingiu praticamente um quarto das organizações $(24,8 \%)$. As tipologias de XCR e XCO reuniram respectivamente 11,5\% e $10,5 \%$ das provas, seguidas dos eventos de Challenge com $6,4 \%$ e das disciplinas de Downhill e Enduro que tiveram $4,4 \%$ e $3,0 \%$ respectivamente. Os eventos de UpHill e de Contra-relógio foram os mais raros com 6 e com 1 prova.

\begin{tabular}{|c|c|c|c|c|c|c|c|c|c|c|}
\hline \multirow[t]{2}{*}{ Tipologia } & \multicolumn{2}{|c|}{ Eventos } & \multicolumn{2}{|c|}{ Percursos (n) } & \multicolumn{3}{|c|}{ Inscritos (n) } & \multicolumn{3}{|c|}{ Preços $(€)$} \\
\hline & (n) & $(\%)$ & nTP & $\mathrm{M}$ & $\mathrm{nE}$ & $\mathrm{M}$ & Max & $\mathrm{n} \epsilon$ & $\mathrm{M}$ & Max \\
\hline $\mathrm{XCM}$ & 260 & $38.4 \%$ & 478 & 2.03 & 166 & 313 & 2700 & 157 & 10.72 & 35.00 \\
\hline Passeio & 168 & $24.8 \%$ & 207 & 1.46 & 66 & 184 & 1229 & 76 & 8.25 & 15.99 \\
\hline XCR & 78 & $11.5 \%$ & 44 & 1.00 & 45 & 118 & 426 & 30 & 12.48 & 32.00 \\
\hline $\mathrm{XCO}$ & 71 & $10.5 \%$ & 16 & 1.00 & 17 & 71 & 295 & 2 & 9.00 & 10.00 \\
\hline Challenge & 43 & $6.4 \%$ & 34 & 1.17 & 11 & 158 & 360 & 9 & 271.67 & 1975.00 \\
\hline Downhill & 30 & $4.4 \%$ & 2 & 1.00 & 12 & 98 & 400 & 0 & - & - \\
\hline Enduro & 20 & $3.0 \%$ & 1 & 1.00 & 6 & 98 & 277 & 0 & - & - \\
\hline UpHill & 6 & $0.9 \%$ & 3 & 1.00 & 2 & 56 & 69 & 3 & 6.00 & 7.00 \\
\hline Contra-relógio & 1 & $0.1 \%$ & 1 & 1.00 & 1 & 48 & 48 & 1 & 7.50 & 7.50 \\
\hline Total & 677 & $100.0 \%$ & 783 & 1.51 & 326 & 228 & 2700 & 278 & 18.60 & 1975.00 \\
\hline
\end{tabular}

Os 783 percursos postos à disposição dos participantes foram contabilizados a partir de 474 eventos (70\% dos 677). Dos restantes, cerca de 152 correspondem a tipologias como o XCO, XCR, Enduro e o Uphill que normalmente têm apenas uma distância, podendo afirmar-se que em 2018 os eventos de BTT em Portugal promoveram mais de 1000 traçados. Em regra, os eventos XCM contam com 2,03 distâncias, os Passeios com 1,46 e as provas Challenge contam com 1,17. Todas as demais tipologias contam em regra com apenas uma distância.

O número de inscritos foi possível apurar para 326 eventos (48\% do 677) dos quais resultou uma média total de 228 participantes por prova. Neste indicador é de registar que existe uma grande variação de inscritos por tipologia. Os eventos de XCM, seguidos dos Passeios e dos eventos de Challenge são quem mais participantes conseguem reunir, em oposição aos eventos de Uphill e Contra-relógio. Os eventos de XCR, Downhill, Enduro e de XCO situam-se num patamar intermédio com médias entre os 71 e os 118 participantes.

De entre os 372 eventos (55\% dos 677) para os quais se conseguiu apurar o preço de inscrição, a tipologia mais cara corresponde aos eventos Challenge com valor médio de 270 euros e um máximo de 1975 euros. Sem o peso deste preço da TransPortugal Tour que inclui 14 etapas para um total de $1100 \mathrm{~km}$ o valor médio desta tipologia de acordo com os dados apurados desce para os 60 euros. Regra geral, esta tipologia incluí mais de um dia de prova e serviços muito para além do preço básico de participação num evento 
desportivo como refeições e dormida ou local de acampamento, transporte de bagagens, podendo ainda ser acrescidos de extras como quarto single, massagista, mecânico, etc. O preço de inscrição incluí normalmente o direito a participar, reforço alimentar, seguro, banho e eventualmente um brinde ou mesmo uma refeição de confraternização no final do evento (o que sucedeu em 16\% dos 186 eventos em que se apurou o preço do almoço). Os preços médios para as tipologias XCM, Passeio, XCR e XCO situam-se entre 8 euros e os 12 euros e os preços máximos a variarem entre os 10 euros e os 35 euros. As tipologias de Uphill e Contra-relógio são de acordo com os dados recolhidos as mais económicas. Ainda que raros, foram encontrados três eventos (dois XCM e um passeio) em que a participação foi gratuita, ainda que de inscrição obrigatória por causa do seguro.

\section{Comprimento dos percursos}

De entre todas as tipologias, a que apresenta maiores distâncias como seria de esperar é a dos eventos Challenge cujo percurso mais longo foi a da TransPortugal Tour com $1100 \mathrm{~km}$. Seguem-se os eventos de XCM, os Passeios e o Enduro (ainda que para esta tipologia só se tenha confirmado uma distância entre os 20 eventos identificados), e as provas de Downhill e circuito (XCR, XCO e Contra-relógio). Os eventos de Uphill são os de distâncias mais curta registando o record de menor distância com $265 \mathrm{~m}$ para a «Subida à Glória Jogos Santa Casa 2018» realizado em Lisboa. O comprimento médio das 783 distância apuradas foi de $50,6 \mathrm{~km}$.

Apesar do carácter competitivo dos eventos de XCM alguns apresentam propostas de menor distância (entre os 10 e os $25 \mathrm{~km}$ ) nos mesmos moldes dos Passeios e muitas vezes guiados. Os comprimentos médios das distâncias das tipologias mais populares (XCM e Passeios) cifram-se na ordem dos 54,4, 37,7 e 27,5 km como se pode ver na Figura 2. A distância 4, é rara, tendo sido encontrada apenas em quatro situações.

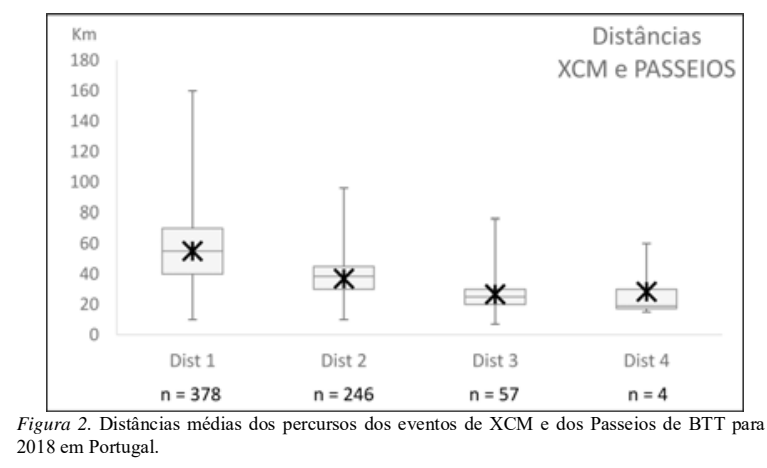

Ainda que os eventos de circuito ofereçam apenas um traçado existem algumas provas de XCR em que à semelhança das tipologias de XCM e dos Passeios, oferecem mais de uma duração ou a possibilidade de participar a solo ou em equipas (duplas, mistas, etc.).

Por último é de registar que a tipologia Challenge funciona muitas vezes de uma forma adaptável às preferências dos participantes: normalmente há uma distância total que soma o prólogo inicial e as diferentes etapas, mas podem existir participantes que participem apenas numa etapa em particular.

\section{Análises temporal}

\section{Edições e Longevidade}

Em relação à análise do número de edições, esta baseiase apenas em 55\% dos 677 eventos de BTT identificados. Observando a Figura 3 verificam-se claramente dois períodos destintos separados por um momento chave que se passou em 2005 com um aumento de $650 \%$ de novos eventos por comparação com o ano de 2004. O primeiro período, entre 1995 e 2004 do qual ainda se realizam cerca de 20 eventos representando os primórdios da disseminação dos eventos e BTT em Portugal. O segundo período de $2006 \mathrm{em}$ diante, que regista uma taxa de crescimento média de novos eventos na ordem dos $20 \%$, ainda que marcada por oscilações e 4 anos de crescimento negativo: 2006, 2010, 2016 e 2018.

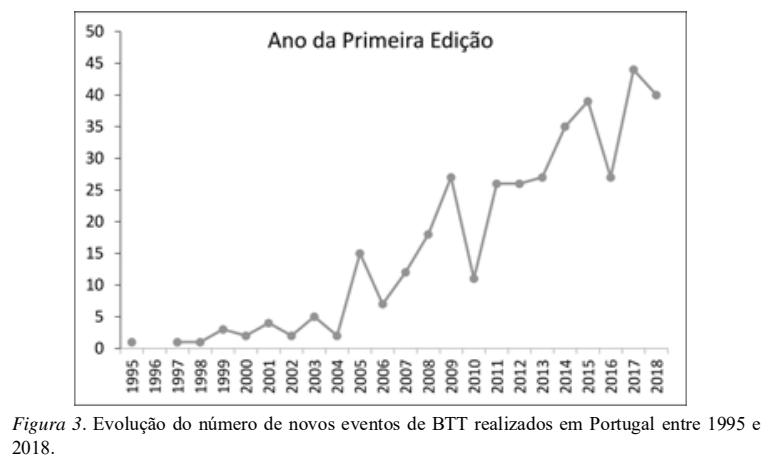

Dos 302 eventos para os quais não se conseguiu apurar de forma taxativa a edição, há que registar que 108 indicam no seu nome a tratar-se da edição de «2018», tratando-se muito provavelmente de eventos com mais de uma edição.

Padrões de Distribuição Sazonal e Semanal

A distribuição anual aos eventos de BTT em Portugal, revela uma distribuição bimodal com a maioria dos eventos e

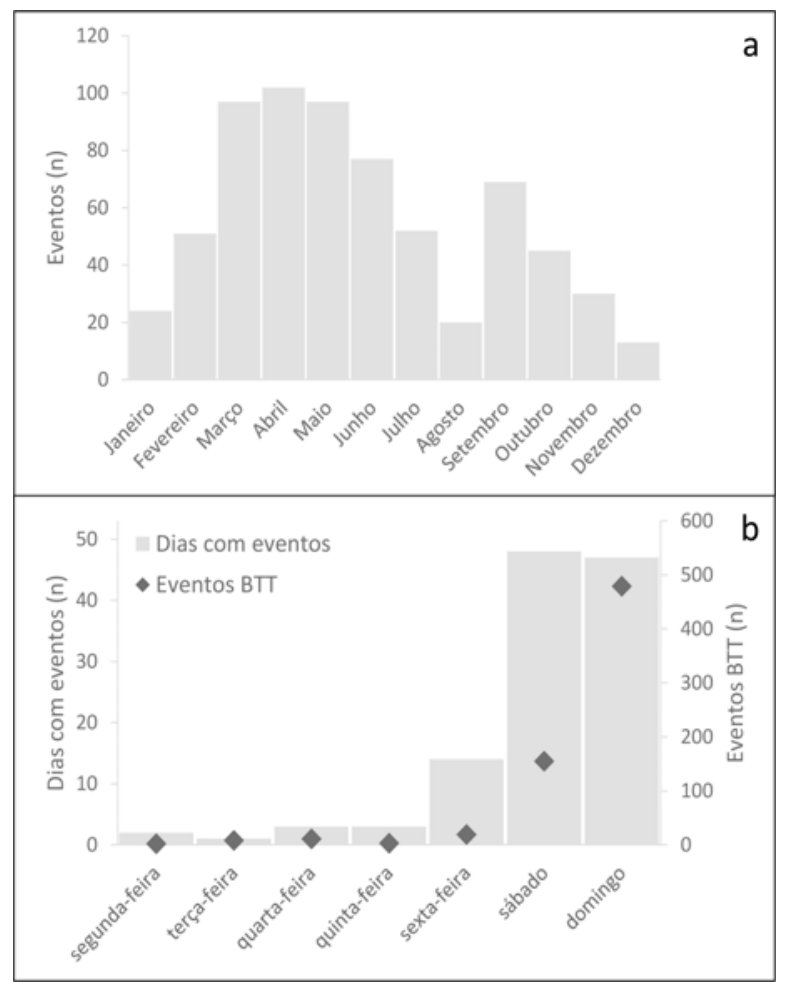

Figura 4. Padrão de distribuição mensal e sazonal dos eventos de BTT em Portugal em 2018 
um primeiro pico a acorrer durante os meses de Primavera (de Março a Junho) e o segundo pico durante os meses de Outono (Figura 4a). Abril foi mês com maior número de eventos - 102 e Janeiro, Agosto e Dezembro foram os meses com menor número de provas -24, 20 e 13 respectivamente. Em relação aos dias de semana, Domingo é o dia com mais registo de eventos com 479, seguido de Sábado com 155 (Figura $4 b)$.

Quanto aos eventos realizados nos dias de semana (43 no total) estes correspondem a feriados nacionais (com 22 casos) como os dias 30 de Março (Sexta-feira Santa), 25 de Abril (Dia da Liberdade), 1 de Maio (Dia do Trabalhador), 31 de Maio (Corpo de Deus), 5 de Outubro (Dia de Implantação da República). Os restantes 21 casos correspondem eventos nocturnos, prólogos de eventos de Challenge (normalmente à sexta-feirta), competições internacionais ou feriados de âmbito local.

\section{Distribuição espacial e ocorrência eventos de BTT}

Em relação à espacialização, os dados demonstram que distribuição de eventos segue em regra a densidade populacional do Pais existindo uma correlação positiva de 0,2495 entre população residente e número de eventos por distritos. Distritos com maior número de residentes (zonas costeiras) têm mais eventos e distritos com menor residentes (interior) têm menos eventos como se pode ver Tabela 4 e Figura 5. Bragança com 9 eventos, é o distrito com menor número de provas sendo que todos ocorrem dentro ou na proximidade de uma área protegida ou classificada. Braga, com 66 eventos é o distrito com maior número de eventos, concentrando $9,7 \%$ do total das provas do País, sendo o distrito com menor percentagem de eventos a iniciar dentro ou na proximidade de uma área protegida ou classificada.

\begin{tabular}{|c|c|c|c|c|c|c|c|c|}
\hline \multirow{2}{*}{ Distrito } & \multirow{2}{*}{$\begin{array}{c}\text { População } \\
\text { Residente }\end{array}$} & \multirow[b]{2}{*}{$\%$} & \multicolumn{6}{|c|}{ Eventos } \\
\hline & & & Total & $\%$ & RNAP & $\%$ & SNAC & $\%$ \\
\hline Aveiro & 714197 & $6.8 \%$ & 24 & $3.5 \%$ & 0 & $0.0 \%$ & 16 & $66.7 \%$ \\
\hline Beja & 152758 & $1.4 \%$ & 42 & $6.2 \%$ & 9 & $21.4 \%$ & 20 & $47.6 \%$ \\
\hline Braga & 848185 & $8.0 \%$ & 66 & $9.7 \%$ & 6 & $9.1 \%$ & 19 & $12.1 \%$ \\
\hline Bragança & 136252 & $1.3 \%$ & 9 & $1.3 \%$ & 8 & $88.9 \%$ & 9 & $100.0 \%$ \\
\hline Castelo Branco & 196264 & $1.9 \%$ & 22 & $3.2 \%$ & 12 & $54.6 \%$ & 16 & $54.5 \%$ \\
\hline Coimbra & 430104 & $4.1 \%$ & 35 & $5.2 \%$ & 1 & $2.9 \%$ & 18 & $42.9 \%$ \\
\hline Évora & 166726 & $1.6 \%$ & 31 & $4.6 \%$ & 1 & $3.2 \%$ & 16 & $32.3 \%$ \\
\hline Faro & 451006 & $4.3 \%$ & 50 & $7.4 \%$ & 20 & $40.0 \%$ & 47 & $90.0 \%$ \\
\hline Guarda & 160939 & $1.5 \%$ & 23 & $3.4 \%$ & 9 & $39.1 \%$ & 15 & $47.8 \%$ \\
\hline Leiria & 470922 & $4.5 \%$ & 38 & $5.6 \%$ & 15 & $39.5 \%$ & 27 & $68.4 \%$ \\
\hline Lisboa & 2250533 & $21.3 \%$ & 45 & $6.6 \%$ & 26 & $57.8 \%$ & 30 & $64.4 \%$ \\
\hline Portalegre & 118506 & $1.1 \%$ & 22 & $3.2 \%$ & 10 & $45.5 \%$ & 21 & $86.4 \%$ \\
\hline Porto & 1817175 & $17.2 \%$ & 54 & $8.0 \%$ & 9 & $16.7 \%$ & 17 & $27.8 \%$ \\
\hline Santarém & 453646 & $4.3 \%$ & 46 & $6.8 \%$ & 10 & $21.7 \%$ & 17 & $34.8 \%$ \\
\hline Setúbal & 851258 & $8.1 \%$ & 27 & $4.0 \%$ & 8 & $29.6 \%$ & 19 & $70.4 \%$ \\
\hline Viana do Castelo & 244836 & $2.3 \%$ & 28 & $4.1 \%$ & 9 & $32.1 \%$ & 27 & $96.4 \%$ \\
\hline Vila Real & 206661 & $2.0 \%$ & 24 & $3.5 \%$ & 3 & $12.5 \%$ & 16 & $66.7 \%$ \\
\hline Viseu & 377653 & $3.6 \%$ & 22 & $3.2 \%$ & 0 & $0.0 \%$ & 9 & $22.7 \%$ \\
\hline PT Cont. & 10047621 & $95.1 \%$ & 608 & $89.8 \%$ & 156 & $23.0 \%$ & 359 & $47.0 \%$ \\
\hline R.A.Açores & 246772 & $2.3 \%$ & 46 & $6.8 \%$ & 44 & $95.7 \%$ & 44 & $95.7 \%$ \\
\hline R. A. Madeira & 267785 & $2.5 \%$ & 23 & $3.4 \%$ & 23 & $100.0 \%$ & 23 & $100.0 \%$ \\
\hline TOTAL & 10562178 & $100.0 \%$ & 677 & $100.0 \%$ & 223 & $32.9 \%$ & 426 & $62.9 \%$ \\
\hline
\end{tabular}

De forma genérica em Portugal Continental 23\% dos 608 eventos realizados em 2018 realizam-se na proximidade da RNAP, percentagem que aumenta para $47 \%$ se considerarmos o SNAC. Nas regiões autónomas, usando a mesma distância como unidade, verifica-se que que a $93 \%$ dos eventos dos Açores e totalidade dos eventos da Madeira ocorrem na proximidade das suas áreas protegidas. No total há 426 eventos que ocorrem dentro ou na proximidade de uma área protegida ou classificada, correspondendo a $62,9 \%$ dos 677 .

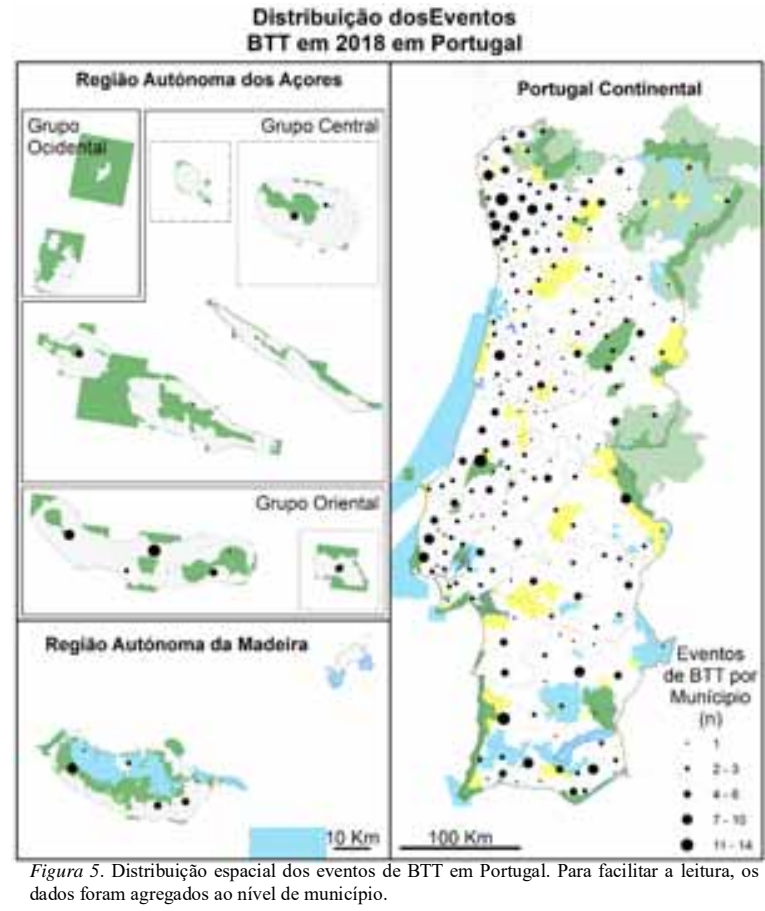

\section{Discussão}

Comparando os 677 eventos de BTT de Portugal (e os seus mais de 1000 percursos) com os 487 eventos (967 percursos) de trail running encontrados por Valente (2019) para o mesmo Ano, podemos concluir que o BTT é uma modalidade bastante popular pelo menos em termos de oferta de eventos. Por comparação com Farías Torbidoni (2015) ainda que a metodologia utilizada não tenha sido a mesma, estes dados sugerem que o «boom» do BTT terá surgido primeiro em Portugal do que no País vizinho. Em 2013 existiram em Espanha 1066 eventos de BTT, com uma taxa de crescimento média de $14 \%$ de novos eventos por Ano desde 2005. Considerando as diferenças em termos de dimensões territoriais e população, quer a própria tradição das modalidades de ar livre e de montanha em Espanha somos obrigados a reconhecer a importância do BTT em Portugal.

Quanto ao número de participantes tendo em conta a falta de consistência das principais fontes consultadas (empresas de cronometragem, a própria UVP-FPC e as associações), quer em quantidade, quer em qualidade é difícil ter uma perspectiva clara do seu verdadeiro número. Algumas fontes revelam o número de inscritos, outras revelam as classificações e os tempos de prova sendo que nenhuma das duas informações representa correctamente o número de participantes à partida para um evento. Nesse sentido, os números médios de inscritos apresentados neste estudo devem ser entendidos como uma primeira abordagem a esta matéria e a esta escala. Na maioria das vezes os dados apresentados pelas empresas de divulgação e cronometragem variam de acordo com os serviços contratados havendo alguns eventos com mais participantes, edições e capacidade organizativa como o «Raid BTT Alvalade de Sado/Porto Covo» que conseguem gerir de forma autónoma cada edição, mas que não mantêm o histórico das anteriores.

Monitorizar estes dados a partir das entidades oficiais não resolve o assunto face à diferença de motivações entre 
atletas competitivos e federados e utilizadores (mesmo que também federados) informais. O número de filiados da federação entre 2014 e 2018 subiu a uma taxa média de 5,6\% ao Ano, mas basta comparar os números oficiais dos atletas das disciplinas de BTT para ver que os resultados deste trabalho devem ser entendidos como exploratórios. De acordo com os dados da UVP-FPC o número médio de participantes das provas do calendário nacional de XCM foi menor que o apurado neste trabalho, 227 atletas contra 313), mas maior nas modalidades de XCO, Downhill e Enduro com 260, 136 e 133 respectivamente (Federação Portuguesa de Ciclismo, 2018).

Ainda em relação ao número de participantes com excepção dos eventos de Uphill e de Contra-relógio, todas as restantes tipologias apresentam valores máximos de inscritos que ultrapassam até oito vezes o número médio de participantes por tipo de evento o que demostra a grande variabilidade deste indicador. Há eventos cancelados por não reunirem uma única inscrição (4), até provas míticas que reúnem alguns milhares de atletas como o «Raid BTT Alvalade de Sado/Porto Covo» com 2700 participantes e cujas primeiras 1500 inscrições se esgotam sistematicamente em menos de um dia. Em média as disciplinas mais técnicas ou fisicamente mais exigentes (Downhill, Enduro, Challenge) e as provas de circuito (XCO e XCR) têm menos inscritos que os eventos de XCM e os Passeios.

Há organizadores que relatam uma quebra do número de inscritos o que tanto se pode dever a uma certa saturação da oferta, como a uma dispersão de ex-praticantes mais assíduos para outras modalidades como o grandfondo ou o trail running. Inquéritos de caracterização desta última modalidade indicam que quase $30 \%$ dos trail runners são ex-praticantes de BTT (Julião et al., 2018). Em relação à possível saturação da oferta há 12 fins de semana com 20 ou mais eventos, cabendo o record ao primeiro fim de semana de Junho com 29 provas. Essa semana contou com 30 eventos, 24 dos quais nesse mesmo domingo. Dos 52 fins de semana de 2018, apenas o último (29 e 30 de Dezembro) não registou qualquer evento de BTT.

Em relação aos preços, e mais uma vez por comparação com o trail running em Portugal cujos valores variam entre 22 41 euros (Valente, 2019), os eventos de BTT são em média mais acessíveis.

Quanto à longevidade dos eventos os resultados encontrados podem estar subavaliados. Em 16,8\% dos 677 eventos é claramente indicada a referência à edição de «2018» 0 que não facilitando a identificação da primeira edição, deixa claramente a ideia de terem existido edições anteriores. Este detalhe levanta a hipótese de um existir um subaproveitamento do prestígio da longevidade de alguns eventos na captação de possíveis interessados. Eventos com mais edições, nem que sejam apenas duas ou três podem facilmente ser entendidos como melhor aposta em termos de organização por oposição a primeiras edições podendo ser importante face à possível saturação da oferta.

A distribuição sazonal e semanal dos eventos de BTT em Portugal, apresenta um padrão idêntico aos dados globais recolhidos por contadores automáticos no Parque Natural da Arrábida (Nogueira Mendes et al., 2012) o que se compreende face ao regime temperado do País. Adistribuição mensal ao longo do Ano é também idêntica aos eventos de trail running para o mesmo ano identificada por Valente (2019).

Em relação à proximidade entre os eventos e as áreas protegidas ou classificadas esta não deve ser entendida como uma razão de causa-efeito, mas não deixa de ser relevante que $29,7 \%$ do território acolham $62,9 \%$ dos eventos. Mesmo deixando de lado as regiões autónomas, onde tanto a orografia do terreno como as tipologias das provas são particulares (mais de metade das provas de Enduro e de Downhill de 2018 aconteceram nos Açores e da Madeira) há $47 \%$ dos eventos de BTT em Portugal Continental o que continua a sugerir uma grande proximidade entre o BTT e o SNAC.

\section{Perspectivas Futuras}

Apesar deste estudo ser uma primeira abordagem feita ao BTT à escala nacional, há outras dimensões desta actividade que têm de ser estudadas, nomeadamente os seus praticantes. Para melhor compreender e gerir a plena potencialidade desta modalidade a nível territorial há que compreender comportamentos, motivações, preferências e expectativas dos praticantes quer dos que participam em eventos, quer dos restantes. Para uma verdadeira monitorização, há que ter ideia da real dimensão do fenómeno, o que neste caso não se limita apenas aos eventos, ainda que, na falta de dados de base possam ser um indicador capaz.

Outro aspecto a analisar, prende-se com a evolução dos próprios eventos quer a nível de edições anteriores ou futuras, quer a nível de distâncias, percursos, inscritos e preços. Apesar das dificuldades da recolha dos dados, há casos suficientes em todos estes indicadores para poder melhorar o conhecimento desta matéria e confirmar se outras modalidades ou novas modas como os grandfondo ou o trail running retiram de facto praticantes ao BTT, ou se os padrões de deslocação em torno da prática da modalidade se alteraram.

Por fim, e tendo em conta a importância do BTT para os territórios das áreas protegidas e classificadas faz sentido promover uma avaliação a nível local e regional de impactos económicos e ambientais. As áreas protegidas e classificadas são áreas com princípios de desenvolvimento que assentam em torno da sustentabilidade, da biodiversidade e da conservação e manutenção de espécies e habitats o que implica fortes restrições em relação a outros modelos. A avaliação económica destes eventos, ou da modalidade em geral pode ajudar a promover estratégias mais compatíveis com esses princípios, o que implica uma consciência real dos impactos no sentido de serem evitados ou mitigados.

\section{Conclusões}

Os resultados deste estudo demonstram que há uma distribuição nacional dos eventos de BTT e que estes se caracterizam por terem em média 1,5 percursos (variando entre 1 e 4) com um comprimento médio de $50,6 \mathrm{~km}$ no qual se inscrevem 228 participantes. Face às diferentes tipologias, há que reconhecer, no entanto, que estes indicadores são bastante heterogéneos. Em termos sazonais, a maioria dos 
eventos realiza-se nos meses de Primavera, seguindo o período outonal apesar de existirem provas espalhadas ao longo de todo o Ano.

$\mathrm{Na}$ falta de dados sistematizados, ficou patente que fontes de dados secundárias são válidas o suficiente para reunir dados importantes contribuindo para a compreensão de modalidades com um grande peso informal como acontece o BTT. Não substituindo de todo os métodos de observação directa, face ao peso das tecnologias de informação e comunicação dos dias de hoje, é justo assumir que estes representam com propriedade estas modalidades tendo custos operacionais bastante mais acessíveis que os métodos de observação clássicos.

Face ao objectivo genérico deste estudo, pode afirmarse que foi dado um passo importante na construção da necessária imagem do BTT a nível nacional em Portugal. O levantamento e os resultados alcançados permitem o estabelecimento de uma situação de referência que poderá ser comparada nos seus diferentes indicadores com o passado e o futuro da modalidade. A metodologia aplicada provou essa validade, prestando-se seguramente para outras modalidades recreativas de ar livre e podendo por isso ser um contributo positivo para a gestão do território

Como principal conclusão deste estudo há que eleger que as áreas protegidas são territórios atractivos para o desenrolar de eventos e desportos de ar livre. A proximidade entre estes eventos e estes territórios não é aleatória merecendo por isso uma atenção especial a nível da gestão. Programas especiais como o Programa Nacional de Turismo de Natureza ou estratégias de desenvolvimento do sector e destes territórios podem ser excelentes promotores dessa atenção. Ordenar a oferta pode ajudar a diminuir e limitar os muitos conflitos ambientais e sociais reconhecidos para o BTT, da mesma forma que o podem fazer para outros eventos ou modalidades.

\section{Agradecimentos}

Os autores agradecem o apoio do Institut Nacional d’Educació Física de Catalunya e o financiamento deste trabalho por fundos nacionais através da FCT - Fundação para a Ciência e a Tecnologia, I.P., no âmbito do projecto «UIDB/04647/2020» do CICS.NOVA-Centro Interdisciplinar de Ciências Sociais da Universidade Nova de Lisboa.

\section{Referências}

Ainsworth, B. E., Haskell, W. L., Herrmann, S. D., Meckes, N., Bassett, D. R., Tudor-Locke, C., ... Leon, A. S. (2011). 2011 compendium of physical activities: A second update of codes and MET values. Medicine and Science in Sports and Exercise, 43(8), 1575-1581. https://doi.org/ 10.1249/MSS.0b013e31821ece12

Brown, K. M. (2016). The role of belonging and affective economies in managing outdoor recreation: Mountain biking and the disengagement tipping point. Journal of Outdoor Recreation and Tourism, 15, 35-46. https://doi.org/ 10.1016/j.jort.2016.07.002

Campelo, M. B., \& Nogueira Mendes, R. M. (2016). Comparing webshare services to assess mountain bike use in protected areas. Journal of Outdoor Recreation and Tourism, 15, 82-88. https://doi.org/10.1016/ j.jort.2016.08.001

Cordell, H. K., Betz, C. J., Mou, S. H., \& Gormanson, D. D. (2012). Outdoor Recreation in the Northern United States. https://doi.org/10.1080/ 07060660809507544

European Union. (2018). Special Eurobarometer 472 Sport and physical activity. https://doi.org/10.2766/483047

Farías-Torbidoni, E. I. (2015). Minimització dels impactes mediambientals en els esdeveniments esportius en el medi natural: les marxes de bicicleta tot terreny Minimization. Apunts. Educacion Fisica y Deportes, (122), 68 80. https://doi.org/10.5672/apunts.2014-0983.es.(2015/4).122.08

Farías, E., Seguí, J., Mena, X., \& Sabaté, A. (2017). Eventos deportivos en espacios naturales protegidos. El caso de la red de Espacios Naturales de Protección Especial de Cataluña. EUROPARC España, (Junio), 29-31.

Federação Portuguesa de Ciclismo. (2018). Relatorio de Atividades e Contas 2018. Retrieved from https://www.fpciclismo.pt/relatorio-e-contas-2018

Fuster Matute, J., Farias Torbidoni, E. I., Gil, G., \& Seguí Urbaneja, J. (2014). Análisis de Trekorientación ${ }^{\circledR}$ Bosque de Poblet: un evento deportivo sostenible en el medio natural. Apunts. Educación Física y Deportes, 115(1), 61-71. https://doi.org/http://dx.doi.org/10.5672/apunts.20140983.es.(2014/1).115.06

IMBA Europe. (2015). European Mountain Bike Survey. Retrieved from www.imba-europe.org/locations

Julião, R. P., Farias-Torbidoni, E., Valente, M., \& Mendes, R. (2018). Análise comparada dos praticantes de Trail Running em contexto ibérico. In J. A. R. Fernandes, J. Olcina, M. L. Fonseca, E. M. da Costa, R. Garcia, \& C. Freitas (Eds.), XVI Colóquio Ibérico de Geografia Colóquio Ibérico de Geografia/ XVI Coloquio Ibérico de Geografía (pp. 776-783). Lisboa: Centro de Estudos Geográficos da Universidade de Lisboa. https://doi.org/ 10.33787/CEG20190003

Kollar, C. D. (2011). Characterizing Mountain Biking Use and Biophysical Impacts through Technical Trail Features: A Case Study of A Montane and A Coastal Plain Site in The U.S.A. North Carolina State University.

López-Carril, S., Villamón, M., \& Añó, V. (2019). Conceptualización de los medios sociales: oportunidades para la gestión del deporte. RETOS. Nuevas Tendencias En Educación Física, Deporte y Recreación, 36, 578-583.

National Survey on Recreation and the Environment (NSRE): 2000-2002. The Interagency National Survey Consortium, Coordinated by the USDA Forest Service, Recreation, Wilderness, and Demographics Trends Research Group, Athens, GA and the Human Dimensions Research Laboratory, University of Tennessee, Knoxville, TN.

Nogueira Mendes, R. M., \& Pereira da Silva, C. (2016). Organized mountain biking events within peri-urban protected areas. How many are too many? In Đ. Vasiljeviæ, M. Vujièiæ, L. Laziæ, \& V. Stojanoviæ (Eds.), The 8th International Conference on Monitoring and Management of Visitors in Recreational and Protected Areas (MMV) (pp. 120-122). Novi Sad: Department of Geography, Tourism and Hotel Management.

Nogueira Mendes, R. M., Silva, A., Grilo, C., Rosalino, L. M., \& Pereira da Silva, C. (2012). MTB Monitoring in Arrábida Natural Park, Portugal. In P. Fredman, M. Stenseke, H. Liljendahl, A. Mossing, \& D. Laven (Eds.), The 6th International Conference on Monitoring and Management of Visitors in Recreational and Protected Areas (MMV) (pp. 32-33). Stockholm.

Parra Camacho, D., Calabuig Moreno, F., Añó Sanz, V., Ayora Pérez, D., \& Núñez Pomar, J. M. (2014). El impacto de un evento deportivo mediano: percepción de los residentes de la comunidad de acogida. RETOS. Nuevas Tendencias En Educación Física, Deporte y Recreación, (26), 88-93.

Pickering, C. M., Hill, W., Newsome, D., \& Leung, Y.-F. (2010). Comparing hiking, mountain biking and horse riding impacts on vegetation and soils in Australia and the United States of America. Journal of Environmental Management, 91(3), 551-562. https://doi.org/10.1016/ j.jenvman.2009.09.025

Santos, T., Nogueira Mendes, R., \& Vasco,A. R. (2016). Recreational activities in urban parks: Spatial interactions among users. Journal of Outdoor Recreation and Tourism, 15, 1-9. https://doi.org/10.1016/ j.jort.2016.06.001

Savre, F., Saint-Martin, J., \& Terret, T. (2010). From Marin County's Seventies Clunker to the Durango World Championship 1990: A History of Mountain Biking in the USA. International Journal of the History of Sport, 27(11), 1942-1967. https://doi.org/10.1080/09523367.2010.491624

Segui Urbaneja, J., \& Farías Torbidoni, E. I. (2018). El trail running (carreras de o por montaña) en España. Inicios, evolución y (actual) estado de la situación. Retos, 33(33), 123-128.

Valente, M. S. da S. (2019). Desportos de Natureza e Espaços Naturais: Análise Espacial do Trail Running em Portugal. Universidade Nova de Lisboa. http://hdl.handle.net/10362/92941

Warnick, R. B. (2005). Back to the future: trends In northeast recreation, tourism and future research. A founders' forum presentation. In Proceedings of the 2005 northeastern recreation research symposium (pp. 110-118). 